\title{
Trap Sequence and its Consequences
}

\author{
Natalija Vedmedovska*, Dace Rezeberga*,** \\ *Riga Maternity Hospital, Riga, Latvia \\ **Department of Obstetrics and Gynaecology, Riga Stradins University, latvia
}

\begin{abstract}
Summary
TRAP sequence-is a rare, serious malformation with reported incidence 0.3 in 10.000 pregnancies. The prognoses is lethal for the recipient, whereas perinatal mortality and malformation risks are up to $50 \%$ and $10 \%$ in pumping twin.

We present three cases of TRAP sequence diagnosed and followed at our institution from August to October 2011.

Outcome of TRAP sequence depends on the time of diagnoses, treatment modality and timely delivery.

Key words: Acardiac twin, TRAP sequence, fetoscopic Radiofrequent ablation
\end{abstract}

\section{AIM OF THE DEMONSTRATION}

Acardiac twinning or TRAP (Twin reversed arterial perfusion) sequence is a rare, but serious malformation with reported incidence 0.3 in 10.000 pregnancies (8). This complication occures in $1 \%$ of monozygotic twins (1). Pathophysiology includes abnormal vascular anastomoses in the placenta with reversal flow in the acardiac twin (7). The antenatal diagnosis of TRAP sequence can be established during the first-trimester screening $(5,12)$.

We present three cases of TRAP sequence diagnosed and followed at our institution from August to October 2011. In two cases fetoscopic Radiofrequent ablation (RAF) was performed in Luven University Hospital, Belgium.

\section{CASE REPORT 1}

A 40-year-old lady, (G7P0, intracytoplasmic sperm injection /embrio transfere) was refered for the second opinion scan at $23+4$ weeks of gestational. Ultrasound revealed monochorionic, biamniotic twin pregnancy with one normally appearing retarded fetus with abnormal venous Doppler. A single large placental mass was located in the fundal region. The second fetus had an incompletely formed skeleton, partly formed head and an abdominal stump without any intraabdominal organs $95 \times 54 \times 45 \mathrm{~mm}$ in size; there were one well-developed lower limb which showed massive, diffuse, soft tissue edema (Fig.1). The umbilical cord of the abnormal fetus had a single umbilical artery. This appearance was typical for TRAP sequence with an acardiac twin. Uncomplicated radiofrequent ablation (RAF) was performed in Luven University Hospital (Fig.2). After invasive procedure this patient was followed-up with serial ultrasound examinations. Cesarean section was performed at $31+3$ weeks due to premature rupture of membrane. Severely retarded girl $(716 \mathrm{~g})$ was born with Apgar scores 4/6/7 in 1/5/10 minutes. The newborn experienced necrotizing colitis, laparotomy due to volvulus and congenital narrowing of jejunum, septic shock, and intraventricular heamorrhage. At her 6 corrected monthes of life her weight was $4500 \mathrm{~g}, 55 \mathrm{~cm}$ length with severely increased tone in extremities.

\section{CASE REPORT 2}

A 28-year -old lady (G2P2) was referred for a second opinion anomaly scan. TRAP sequence was confirmed at $16+6$ weeks of gestation. The anomalous fetus was an amorphous heterogeneous mass; it had an abdominal stump $80 \times 40 \mathrm{~mm}$ with an echogenic structure that resembled the spine. It had both small lower and upper limbs; their autonomous movements were registered. Surviving fetus was consistent with $15+6$ weeks of gestation, growth restricted, but with normal Doppler. After RAF procedure ex-pumping twin grew apropriately; 4 weeks after invasion resumed vascularisation in acardiac twin. Antenatal death of surviving fetus was confirmed at admission at $38+6$ weeks. Birth weight of macerated neonate was $2760 \mathrm{~g}$. Partly mumified acardiac fetus was born together with placenta [Fig.3].

\section{CASE REPORT 3}

In a 31-year-old lady (G5P2) TRAP sequence was confirmed at $16+5$ weeks. In surviving fetus multiple anomalies-ventriculomegaly, ventricular septal defect, hypoplastic kidneys were revealed in the presence of kariotype 46XX. The labour was induced due to antenatal death of pumping fetus at 26 weeks of gestation.

\section{DISCUSSION}

The first time acardiac malformation was discribed by Benedetti in 1553. The artery-to-artery anastomosis in fused placenta between twins lead to the retrograde perfusion of deoxygenated blood from pump foetus to "recipient" twin, resulting in variaty structural abnormalities in the latest (10). Acardiac twin never survive, and the perinatal mortality of the pump twin is reported to be around $50 \%$ (4). The poor outcome of the pump twin is primarily due to congestive heart failure, prematurity or major malformations (9). The early recognition of this abnormality in the antenatal period becomes important for the proper management. Management options include elective termination, observation, selective nonsurgical and surgical interventions. Different surgical techniques have been 
applied $(2,6)$. Elective reduction of the acardiac twin with RFA was found to be minimally invasive and effective. That therapeutic intervention before the onset of intrauterine fetal complications became available recently either for Latvian citizens in Luven University Hospital (European project N E112). Studies place the safest time for delivery of twin pregnancies at 36 to 38 weeks (3). That makes us think that case 2 would have another, more favorable outcome if induced earlier. Therefore outcome of pregnancy with TRAP sequence depends on the time of diagnoses, treatment modality and timely delivery.

\section{Conflict of interest: None}

\section{REFERENCES}

1. Barth RA, Crow HC. Ultrasound evaluation of multifetal gestations // In: Callen PW, editor. Callen ultrasonography in obstetrics and gynaecology. 4th ed. Pennsylvania: W B Saunders; 2000; $196-8$

2. Diehl W, Hecher K. Selective cord coagulation in acardiac twins // Semin Fetal Neonatal Med, 2007; $12: 458-63$

3. Dodd J, Crowther C, Haslam R, Robinson J. Elective birth at 37 weeks gestation safer for mothers carrying uncomplicated twins at term: the Twins Timing of Birth Randomised Trial // BJOG, 2012; 1 19:964 - 974

4. Gembruch U, Viski S, Bagamery K, Berg C, Germer $\mathrm{U}$. Twin reversed arterial perfusion sequence in twin-to-twin transfusion syndrome after the death of the donor co-twin in the second trimester // Ultrasound Obstet Gynecol, 2001; 17:153 - 6

5. Hartge DR, Weichert J. Prenatal diagnosis and outcome of multiple pregnancies with reversed arterial perfusion (TRAP-sequence) // Arch Gynecol Obstet, 2012; 286:81 - 8

6. Ichizuka K, Hasegawa J, Nakamura M, Matsuoka R, Sekizawa A, Okai T, Umemura S. A Clinical Trial of Ultrasound Treatment for TRAP Sequence // Ultrasound in Obstetrics Gynecology, 2012; DOI: $10.1002 /$ uog. 11114

7. Levi CS, Lyons EA, Martel MJ. Sonography of multifetal pregnancy // In: Carol M, Rumack, editors. Diagnostic ultrasound. 3rd ed. Vol. 2. Missouri: Elsivier Mosby; 2005; 1207 - 9

8. Monteagudo A, Ashley S. Roman Ultrasound in Multiple Gestations: Twins and Other Multifetal Pregnancies // Clin Perinatol, 2005; 32: 329 - 354

9. Moore T, Gale S, Benirschke K. Perinatal outcome of forty-nine pregnancies complicated by acardiac twinning // Am J Obstet Gynecol, 1990; 163:907 912

10. Shih JC, Shyu MK, Hunag SF, et al. Doppler waveform analysis of the intertwin blood flow in acardiac pregnancy: implications for pathogenesis // Ultrasound Obstet Gynecol, 1999; 14: 375 - 9

11. Tsao K, Feldstein VA, Albanese CT, et al. Selective reduction of acardiac twin by radiofrequency ablation // Am J Obstet Gynecol, 2002; 187: 635 40
12. Weisz B, Peltz R, Chayen B, et al. Tailored management of twin reversed arterial perfusion(TRAP) sequence // Ultrasound Obstet Gynecol, 2004;23:451 - 5

Address:

Natlija Vedmedovska

Riga Stradins University,

Dzirciema street 16,

Riga, LV - 1007, Latvia

E-mail: natalyved@apollo.lv

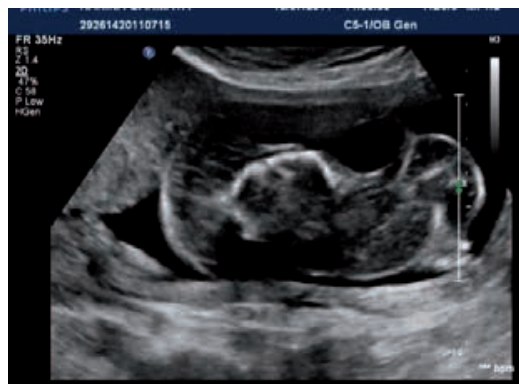

Fig.1. Case 1: Transabdominal USG shows the abdominal stump of the abnormal fetus demonstrating heterogeneous echotexture, without any discernable internal organs with diffuse massive soft tissue edema

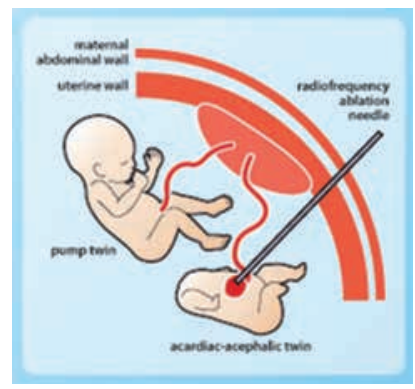

Fig.2 Radiofrequency ablation technique. Procedure performed by single puncture with a 17-gauge needle $1 \mathrm{~mm}$ diameter in size, using real-time ultrasound guidance. In utero time is $15 \mathrm{~min}$, intra fetal time of RFA is 10 minutes. Tips temperature is $20^{\circ} \mathbf{C}$. Adapted from http://fetus.ucsfmedicalcenter. org/twin/learn_more_trap.asp

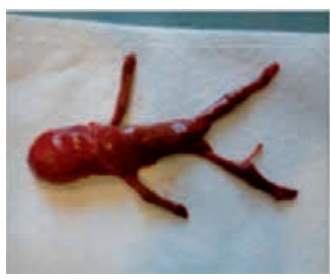

Fig.3 Case 2: Partly mumified acardiac fetus, which was born together with placenta. We can see both lower and upper extremities, that continued to grow after resuming of vascularization 